Eloy Espinosa-Saldaña Barrera(*)

\title{
Cuando el juez(a) constitucional latinoamericano(a) olvida su labor de Convencionalización del Derecho: reflexiones en torno a una reciente sentencia de la Corte Suprema de Justicia de la Nación argentina ${ }^{(*)}$
}

\author{
When the Latin American constitutional judge forgets his/her job of \\ conventionalization of law: reflections about a recent sentence of the \\ Argentine Supreme Court of Justice.
}

\author{
A PESAR DE LA DESCONFIANZA, EN AMÉRICA LATINA TRADICIONAL, CUANDO NO ENDÉMICA; \\ EN LA LABOR DE JUECES Y JUEZAS CONSTITUCIONALES (SOBRE TODO CUANDO QUIENES \\ ESTÁN DENTRO DE LA JUDICATURA ORDINARIA), PRECISAMENTE EN MÉRITO A UN CONTEXTO \\ DIFÍCIL A NIVEL MUNDIAL Y LATINOAMERICANO AL RESPECTO, LAS VENTAJAS DE LA \\ CONVENCIONALIZACIÓN DEL DERECHO SON A TODAS LUCES OSTENSIBLES. AHORA BIEN, \\ ESTA CONVENCIONALIZACIÓN TIENE (Y SEGURAMENTE TENDRÍA) QUE HACER FRENTE A UNA \\ SERIE DE RETOS
}

\begin{abstract}
Resumen: En el presente artículo el autor nos habla sobre la labor del juez constitucional y la importancia que adquiere está en un contexto de crisis. Asimismo, resalta la convencionalización del Derecho como tarea central de los jueces constitucionales. De igual manera, detalla las dificultades que acarrea esta tarea y los retos a enfrentar para la consolidación de un derecho común en América Latina.
\end{abstract}

Palabras clave: Convencionalización del Derecho - Juez Constitucional Derecho Común - Control de Convencionalidad - Latinoamérica

Abstract: In this article, the author tell us about the job of the constitutional judge and the importance that this takes in a context of crisis. Also, he highlights the conventionalization of law as the central task of constitutional

$\left(^{*}\right)$ Magistrado del Tribunal Constitucional del Perú. Abogado por la Pontificia Universidad Católica del Perú. Catedrático en la misma casa de estudios. Correo electrónico: eaespino@pucp.edu.pe

${ }^{* *}$ Nota del Editor: el artículo fue recibido el 27 de mato del año 2017 y su publicación fue aprobada el 20 de junio del mismo año. 
Cuando el juez(a) constitucional latinoamericano(a) olvida su labor de Convencionalización del Derecho: reflexiones en torno a una reciente sentencia de la Corte Suprema de Justicia de la Nación argentina When the Latin American constitutional judge forgets his/her job of conventionalization of law: reflections about a recent sentence of the Argentine Supreme Court of Justice.

judges. Likewise, he details the difficulties involved in this task and the challenges to be faced for the consolidation of a common law in Latin America.

Keywords: Conventionalization of Law - Constitutional Judge Common Law - Conventionality Control - Latin America

\section{Sobre la labor trasformadora que se requiere a un juez(a) constitucional en un contexto de crisis mundial}

La labor del juez(a) constitucional no es tarea sencilla. Se da hoy en una vis expansiva, que le aleja de esa imagen de un legislador(a) negativo(a) adjudicada a Kelsen (la cual hay que preguntarse si alguna vez rigió( $\left.{ }^{(1)}\right)$. En un escenario donde, ante a los cambios existentes, uno se interroga acerca de quién se encarga de qué dentro del Estado Constitucional, se le pide a estos juzgadores(as) impulsar una constitucionalización del Derecho (tanto en sus efectos directos como en los indirectos ${ }^{(2)}$ ); apuntalar una constitucionalización de la política(3); o liderar una convencionalización del Derecho, ya sea interpretando su propio ordenamiento jurídico conforme a tratados como el Convenio Europeo o la Convención Americana, o ejerciendo, en la medida que se encuentre dentro de sus competencias, la inaplicación de la norma considerarla contraria a dicho tratado (en el ejemplo concreto que acabo de plantear, contraria a este Convenio o esta Convención).

También se plantean como responsabilidades del juez(a) constitucional desempeñarse como agente de integración social (con las responsabilidades de cohesión, inclusión, reconciliación y prevención social que aquello involucra), y, last but not least, se le pide un rol de mediación, bajo parámetros jurídicos, frente a los más relevantes problemas políticos, sociales o económicos de una sociedad.
Sin embargo, para el desempeño de tan delicadas tareas, y sobre todo en la de la convencionalización del Derecho, aquella labor que hoy más compromete a estos juzgadores(as) con un rol transformador de sus respectivas sociedades, debe tomarse en cuenta que hay una serie de obstáculos que intentar salvar, o por lo menos, que existen elementos cuyos alcances pueden poner en entredicho lo que tan esforzadamente se quiere obtener. A esos temas dedicaré estas reflexiones, constatando cómo algunas de esas dificultades, por lo menos en Iberoamérica, se han hecho más patentes gracias a una reciente sentencia de la Corte Suprema de Justicia de la Nación argentina. Pasaré entonces a efectuar este análisis de inmediato.

\section{La convencionalización del Derecho como labor central del juez(a) constitucional, sobre todo a nivel latinoamericano. Algunas notas sobre la aspiración de articular nuestros ordenamientos jurídicos estatales con lo dispuesto en el derecho internacional de los derechos humanos. La búsqueda de la construcción de un derecho común}

2.1 Hacia una nueva mirada y eventual reformulación de importantes conceptos Luego de la Segunda Guerra Mundial, y tal

(1) Un desarrollo de nuestro análisis sobre el particular se encuentra en Domingo García Belaunde y Eloy Espinosa-Saldaña Barrera, Encuesta sobre Derecho Procesal Constitucional (México: Porrúa, 2006).

(2) En ese sentido, véase Louis Favoreu, "La Constitucionalización del Derecho". Revista de Derecho de la Universidad Austral de Chile (Valdivia), (agosto 2001), 31-43.

(3) Una explicación de los alcances de este concepto, con especial énfasis a sus implicancias para el caso peruano la tenemos en nuestro "Balance a veinte años de vigencia de la Carta de 1993: Notas sobre el papel del Tribunal Constitucional peruano en la constitucionalización del Derecho y la política, y sus repercusiones". Pensamiento Constitucional 18 (marzo de 2014): 175 y siguientes. 


\section{Eloy Espinosa-Saldaña Barrera}

como ocurrió en otros temas, se va a producir un importante cambio en el escenario del reconocimiento y tutela de los derechos: ya no solamente se cuenta con un nivel interno de protección, sino que dicho reconocimiento y esa tutela se potencia con previsiones en un plano internacional. Ello, como veremos de inmediato, ha tenido un desarrollo que, tomando como referencia lo existente hasta ese instante, tuvo connotaciones a todas luces insospechadas.

Ya con algún tiempo transcurrido desde el final de la Segunda Guerra Mundial, cabe entonces preguntarse sobre el estado de la cuestión al respecto en un contexto tan particular como aquel que actualmente se vive en muchas partes del mundo, y entre ellas en América Latina, en las cuales algunos constatan la existencia de una crisis del Estado (o por lo menos, del modelo de Estado al cual se aspiraba llegar); y otros, con una esperanza basada en una más o menos razonable justificación, consideran encontrarse ante la transformación de nuestras estructuras estatales a un escenario que asumen como cualitativamente mejor.

Es pues sin duda lícito plantearse estas interrogantes en un contexto en el cual se habla del paso de democracias insuficientes (e incluso inexistentes), a lo que varios reputan como su real fortalecimiento, y otros entienden como el riesgo de la instrumentalización de la democracia desde una u otra perspectiva ideológica. Sin duda alguna, dar cabal respuesta a estas preguntas implicaría una interesante y hasta necesaria toma de posición, pero ella desafortunadamente sobrepasa los alcances del presente texto. Ahora bien, y sin que aquello implique eludir esta importante discusión, cierto es que, e independientemente de nuestras perspectivas al respecto, lo que la actual situación latinoamericana permite poner aquí en debate es la cabal materialización de un escenario que se ha venido construyendo, y que se ha ido presentando y asumiendo como ideal.

Me estoy entonces refiriendo a un necesario análisis y debate sobre la consistencia y plena vigencia de la configuración de un ordenamiento jurídico estatal (comenzando por la Constitución de dicho Estado) convencionalizado. $\mathrm{Y}$ es que ya no va a bastar con la incorporación de los tratados sobre Derechos Humanos a la diversa normativa de cada Estado en particular: el ordenamiento jurídico de dichos Estados en su conjunto va a tener que ser leído, comprendido y aplicado conforme a lo previsto en estos tratados, y de acuerdo con parámetros interpretativos más bien propios de aquello que se comprende como dentro del Derecho Internacional de los Derechos Humanos. Ello pasa sin duda por el conocimiento y la comprensión de los derechos previstos en cada ordenamiento interno, y los mecanismos (instituciones y procesos) establecidos en esos mismos ordenamientos para cautelar esos derechos, así como los otros aspectos recogidos en cada Constitución nacional en particular. $Y$ es que no puede comprenderse en clave convencionalizada lo que previamente no se conoce.

Como bien puede apreciarse, va a darse un cambio sobre cómo se van a conocerse y comprenderse los derechos previstos en cada ordenamiento interno y los mecanismos (instituciones y procesos) establecidos en esos mismos ordenamientos para cautelar esos derechos, así como los otros aspectos recogidos en cada Constitución nacional en particular. Es más, hoy vemos cómo cada vez más se consolida una dinámica en la cual hay Estados que progresivamente están más abiertos a sus compromisos internacionales y a las instituciones que se desarrollan, pero también, y al mismo tiempo, se aprecia una preocupación de los tribunales internacionales para la protección de derechos por no solamente establecer una interesante pero insuficiente interacción con los operadores jurídicos de los diferentes Estados. Y es que hoy lo que se busca establecer una lógica de verdadero diálogo mediante la cual se busca la construcción de una plataforma y un Derecho común.

Es en ese sentido que ahora va la labor desde el ámbito de lo internacional. Bien puede constatarse como algunas instituciones internacionales (y sobre todo aquellas responsables de interpretar de manera vinculante lo previsto en los tratados destinados a la tutela de los Derechos Humanos) buscan articular su comprensión de los derechos con 
Cuando el juez(a) constitucional latinoamericano(a) olvida su labor de Convencionalización del Derecho: reflexiones en torno a una reciente sentencia de la Corte Suprema de Justicia de la Nación argentina When the Latin American constitutional judge forgets his/her job of conventionalization of law: reflections about a recent sentence of the Argentine Supreme Court of Justice.

la de los diferentes Estados en particular. Todo lo expuesto va abonando a favor de la consolidación de un Derecho común para varios países, cuyo sustento es la tutela de los derechos de nuestros ciudadanos en base a la interpretación vinculante de los diferentes tratados sobre Derechos Humanos, ya sea porque han sido suscritos por nuestros países o en mérito a que han devenido en normas de ius cogens.

Ahora bien, esta configuración de un Derecho común, proceso en el cual, en lo referido al ámbito latinoamericano, la Corte Interamericana ha ido cumpliendo una muy importante labor, se encuentra muy lejos de estar completo y de no hallarse expuesto a múltiples riesgos.

Estamos pues ante los efectos de dos fenómenos: el que puede apreciarse más directamente es el de la internacionalización, convencionalización o desnacionalización del Derecho (y sobre todo, del Derecho Constitucional, en donde para muchos la soberanía nacional y la Constitución estatal dejan de ser los últimos parámetros de legitimidad del ordenamiento interno). De la mano de esta dinámica va otra, menos perceptible en el tema que vamos a abordar, pero no por ello menos importante. En efecto, también puede producirse la constitucionalización del Derecho internacional (recepción de un lenguaje constitucional y elementos constitucionales en la literatura y la práctica internacionalista, como lo demuestra, por ejemplo, la vocación de algún sector por cierto en una Constitución europea $)^{(4)}$. Ambas confluyen en la configuración del Derecho común al cual venimos haciendo referencia.

Oportuno es anotar que este conjunto de cambios en la comprensión de las cosas es y ha sido resistida hasta hoy por quienes entienden que ella distorsiona conceptos clave para el constitucionalismo como el de la supremacía constitucional, la soberanía estatal o el ilimitado accionar del Poder Constituyente. Confieso que ello, siendo importante, no resulta ahora la preocupación central que motiva este texto: y es que, en cualquier caso, la Constitución sigue siendo la norma que en el entorno estatal sustenta la legitimidad de la actuación de ese mismo Estado en función a ciertos valores, legitimidad que se sostiene en el reconocimiento de un conjunto de principios, derechos, procedimientos y competencias.

Esta relevancia del rol constitucional no cambia entonces si la comprensión de ese papel se realiza en función a pautas voluntariamente asumidas por la decisión soberana de cada Estado en particular, decisión de cumplir compromisos internacionales que aquí (admitiendo que esto último es más polémico) también se nos presentan como el resultado de un consenso generalizado para una cabal vida en comunidad. Como bien señalara Germán Bidart Campos, estos parámetros, voluntariamente asumidos o consensuados, incluso pueden operar como límites heterónomos al constituyente futuro. Son otras las preguntas que aquí quiero responder.

\subsection{El control de convencionalidad como la apuesta hoy más desarrollada para la generación de un Derecho común.}

El proceso de configuración de un Derecho común, por lo menos en América Latina, viene contando con tres instrumentos de vital importancia: el control de convencionalidad, el uso de audiencias y sentencias de seguimiento por la Corte Interamericana y los alcances integrales de las resoluciones emitidas por ese Tribunal de Tutela de Derechos Humanos. Debe entonces tenerse presente que, y dentro de esta búsqueda de convencionalización de los diferentes ordenamientos jurídicos estatales, el control de convencionalidad promovido por la Corte Interamericana de Derechos Humanos (en sede judicial desde Almonacid Arellano (2006), e incluso exigido a la actuación de otras autoridades en el pronunciamiento de supervisión sobre el cumplimiento de la sentencia emitida en casos como el Gelman

(4) Coincido aquí con lo señalado por Manuel Nuñez Poblete, Sobre la doctrina del margen de apreciación nacional. La experiencia Latinoamericana confrontada y el Thelos Constitucional de una técnica de adjudicación del Derecho Internacional de los Derechos Humanos. En Manuel Nuñez Poblete y Paola Andrea Acosta Alvarado, coord., El margen de apreciación en el sistema interamericano de Derechos Humanos: proyecciones regionales y nacionales. (México: Instituto de Investigaciones Jurídicas de la UNAM), 3-4. 


\section{Eloy Espinosa-Saldaña Barrera}

(2013)) posee un papel central en el sistema Interamericano de Derechos Humanos.

Cuando se habla de control de convencionalidad se está haciendo referencia a la labor de contraste entre lo recogido en principio en la Convención Americana (pero también en otros instrumentos internacionales) y la normativa nacional, incluyendo las interpretaciones que le da el juez(a) a toda esa normativa nacional. Se trata de una obligación que deben ejercer de oficio en primer término los jueces (zas) ordinarios (situación ampliada en el caso iberoamericano a otros funcionarios públicos de un Estado en particular, como veremos luego), y luego la Corte complementariamente haga correcciones a la interpretación hecha en el ámbito estatal de considerarlo necesario. Ello en rigor debe entenderse, en primer término, como la obligación de entender los diferentes ordenamientos jurídicos nacionales de acuerdo con parámetros convencionales (interpretación conforme), y, correspondiendo en segundo lugar, como atribución confiada a los tribunales como la Corte Interamericana, así como a aquellas entidades dentro de cada país habilitadas a inaplicar normas por reputarlas inconstitucionales, a dejar de lado una norma interna (aun cuando tenga rango constitucional), y si la misma vulnera o establece menores parámetros de tutela que los parámetros (normativos o jurisprudenciales) de carácter convencional.

La formulación específica del control de convencionalidad, como postura de la Corte Interamericana se plasmó, como ya se adelantó, en Arellano Almonacid vs. Chile (2006), la misma que se ha seguido en casos como Vargas Areco, La Cantuta, entre otros. Incluso dicha formulación ya había sido adelantada en los votos singulares del magistrado Sergio García Ramírez en casos como el de Myrna Mack Chang vs. Guatemala (2003) o López Álvarez vs. Honduras (2006), pero sobre todo en Tibi vs. Ecuador (2004). Incluso cabe alegar que en fallos anteriores de este alto Tribunal ya se habían adelantado criterios similares (en ese sentido puede citarse, por ejemplo, Suárez Rosero vs. Ecuador; Trujillo Oroza vs. Bolivia; Barrios Altos vs. Perú; Palamara Iribarne vs. Chile; Castillo Petruzzi vs. Perú; Trabajadores Cesados del Congreso vs. Perú) $)^{(5)}$.
La configuración de este control de convencionalidad en el Sistema Interamericano de Derechos Humanos ha sido producto de una evolución, la cual ha llevado a que la adecuación de la normativa nacional a los parámetros convencionales (objetivo de esta técnica) implique la adopción de medidas en dos vertientes. Por un lado, la supresión de las normas y prácticas de cualquier tipo que impliquen violación a lo previsto en la Convención u obstaculicen su ejercicio. De otro, la expedición de normas y el desarrollo de prácticas que permitan la cabal observancia de lo prescrito en este importante tratado de Tutela de Derechos Humanos, junto a toda otra convención o declaración del sistema Interamericana (Protocolo de San Salvador, Convención de Belén do Pará para la erradicación de la violencia contra la mujer, etcétera), sentencias y opiniones consultivas de la Corte, que, junto con la Convención Americana, operan como parámetros para el ejercicio de control de convencionalidad en el Sistema interamericano.

Esta evolución del control de convencionalidad también se hace patente en otros importantes aspectos. Uno de ellos es, sin duda alguna, el de los órganos que deben ejercer el control de convencionalidad. Hoy se habla de dos tipos de control de convencionalidad: el concentrado, ejercido por la Corte; y el difuso, por los Estados, a través de sus autoridades.

En este último aspecto se han dado cambios importantes que conviene resaltar: y es que en principio, y de oficio, la labor de control de convencionalidad estaba confiada, dentro de cada Estado, a sus jueces (zas). Ahora bien, y a partir de Cabrera García y Montiel Flores vs. México (2010) o de Gelman vs. Uruguay (2011), y con toda claridad desde la sentencia de

(5) En el mismo sentido, Manuel Arnaldo Castillo Calle, "El control de convencionalidad: criterios con base en la jurisprudencia de la Corte Interamericana de Derechos Humanos," Gaceta Constitucional 71 (Noviembre 2013): 316. 
Cuando el juez(a) constitucional latinoamericano(a) olvida su labor de Convencionalización del Derecho: reflexiones en torno a una reciente sentencia de la Corte Suprema de Justicia de la Nación argentina When the Latin American constitutional judge forgets his/her job of conventionalization of law: reflections about a recent sentence of the Argentine Supreme Court of Justice.

cumplimiento o supervisión de Gelman (2013), la Corte señala que esta labor interpretativa y contralora corresponde a todos los poderes públicos, en tanto operadores del Derecho. Es una postura cuyo valor ético y técnico nadie discute, pero que bien puede generar algunos problemas en su materialización, siendo entonces necesario explicar cuáles son sus alcances, por ejemplo, en lo referente a la inaplicación de normas internas contrarias a parámetros convencionales, tema que, por cierto, hemos tratado de explicar en el presente texto.

Conviene eso sí anotar que existen más aspectos en los cuales bien puede apreciarse esta evolución del control de convencionalidad. En este tenor, es también importante resaltar que en principio no se admitía que esta labor interpretativa y contralora pudiese darse en abstracto: siempre debería llevarse a cabo en función a problemas generados por una aplicación del precepto que viene siendo cuestionado. Sin embargo, esta comprensión de las cosas ha ido variando, acercándose la actual situación a un control abstracto de convencionalidad, tomándose para ello como referencias o antecedentes lo ya planteado, incluso antes del formal establecimiento de esta dinámica contralora, en votos singulares como los de Antonio Cancado Trindade en Genie Lacayo (1995) o El Amparo (1996), o de la postura de la Corte en su conjunto desde Suárez Rosero versus Ecuador (1997).

Los alcances de esta tarea interpretativa y eventualmente contralora (de la cual no escapa norma alguna del ordenamiento jurídico del Estado involucrado) van entonces, como aquí ya se ha dicho, desde la formulación de interpretaciones conformes de lo impugnado (para así asegurar su compatibilidad con el parámetro convencional), hasta la inaplicación o anulación de la normativa o actuación interna cuestionada.

Conviene aquí tener presente que, en la línea de lo que luego veremos acaba de alegar la Corte Suprema argentina, puede darse el eventual alegato de algún Estado en el sentido de que aplicó correctamente el control de convencionalidad. En ese tenor, puede incluso decirse que a la Corte Interamericana le corresponde un rol complementario, y por ende, no le compete pronunciarse sobre lo ya realizado al respecto en un Estado en particular. Ante ello, debe tenerse presente como ya la misma Corte Interamericana, en el caso Cabrera García y Montiel Flores, y ante la excepción deducida por el Estado mexicano en ese sentido, va a anotar que si bien no es un Tribunal de cuarto grado o instancia, en estricta aplicación del principio kompetenz - kompetenz, sí le corresponde verificar si en los pasos seguidos a nivel interno se violaron o no obligaciones del Estado provenientes de los instrumentos interamericanos que le otorgan competencia a ese Alto Tribunal.

Importante es anotar por último que, muy a despecho de su actual amplitud y la lógica expansiva en la cual hoy se desenvuelve el control de convencionalidad, por lo menos en América Latina, lo expuesto nos lleva a un escenario donde incluso cabe inaplicar la norma interna contraria a parámetros provenientes de otros tratados que no son la Convención Americana de Derechos Humanos ${ }^{(6)}$. Ahora bien, justo es volver a anotar que esta postura, técnicamente inobjetable, y tal como veremos luego, tiene también sus problemas o limitaciones para materializarse.

¿Nos encontramos entonces ante un escenario (el de la convencionalización del ordenamiento jurídico estatal) ideal para todos(as)? ¿La lógica que le inspira acoge y respeta el carácter plural de nuestras sociedades en el cual se debate si nos encontramos, por ejemplo, ante parámetros interculturales, multiculturales o pluriculturales, con todo lo que ello involucra? ¿Basta entonces, como señalan algunos defensores de este

(6) Así, por ejemplo, el Tribunal Constitucional peruano, en cumplimiento de tratados vinculados con la lucha contra la corrupción, el narcotráfico y el lavado de activos, ha desarrollado una interpretación convencionalizada de sus competencias que va más allá de lo que pudiera deducirse de una lectura literal de la Constitución hoy vigente en el Perú. En ese sentido, véase al respecto, por ejemplo, lo recogido en la sentencia y en nuestro fundamento de voto en el caso Nadine Heredia Alarcón (STC 05811-2015/HC-TC). 
ideal de convencionalización, con recurrir a modulaciones interpretativas? (Sagués 2013). ¿Puede recurrirse en este escenario al auxilio de técnicas como el margen de apreciación de los Estados, habitualmente utilizado, por ejemplo en el ámbito europeo?

Estamos pues ante un debate de innegable relevancia, en donde difícilmente hay respuestas últimas, finales y rígidas. Por ello, en otro apartado de este mismo trabajo pasaremos pues a realizar algunas aproximaciones conceptuales al respecto, planteando en primer lugar si en el ámbito interamericano, ayuda el contar con mecanismos como el de las audiencias y resoluciones de cumplimiento de sentencias con alcances que se reclaman integrales o, como se invoca más en Europa, sería más bien conveniente recurrir a otras técnicas como el del margen de apreciación de los Estados. Ello nos permitirá luego formular algunas consideraciones sobre cómo en nuestra opinión debe abordarse el tema de las relaciones entre el Derecho interno y lo previsto en el plano del Derecho Internacional de los Derechos Humanos, con normativa, jurisprudencia y prácticas que ya no solamente son parte del Derecho interno, sino que se superponen a aquellos elementos del Derecho interno que le contradigan, o por lo menos, que obstaculicen su materialización.

2.3 El carácter de reparación integral buscado con las sentencias de la Corte Interamericana, su aporte en la configuración de un Derecho común y las dificultades que involucra el cabal cumplimiento de estas resoluciones.

Como se ha anotado en diversos textos, la Corte Interamericana de Derechos Humanos puede establecer diversas medidas de reparación que en un Estado debería cumplir si es condenado en un caso en concreto. Es más, hoy existe cierto consenso en considerar que estas medidas pueden ser agrupadas en medidas de satisfacción medidas de rehabilitación, de restitución y de no repetición.

Medidas de satisfacción: Son aquellas mediante las cuales se busca revertir el perjuicio ocasionado por el incumplimiento de las obligaciones que el Estado tiene de respetar y garantizar los derechos recogidos en la Convención. Son algunas de las medidas de satisfacción pasibles de ser invocadas la publicación de las sentencias o el reconocimiento público de responsabilidad, entre otras.

Medidas de rehabilitación: Son aquellas mediante las cuales se concede asistencia médica y psicológica gratuita e inmediata a las víctimas de violaciones a sus derechos. Son algunas de las medidas de rehabilitación invocables la entrega de medicamentos o la prestación de medicamentos o la prestación de tratamientos especializados, entre otras

Medidas de restitución: Son aquellas mediante las cuales se intenta volver a la situación existente antes de producirse la violación de los derechos de la (s) victima(s). Dentro de estas medidas puede incluirse al pago de indemnizaciones, el pago de costas, el reintegro de gastos, la anulación de antecedentes judiciales y la entrega de la información solicitada.

Medidas de no repetición: Son aquellas mediante las cuales se busca evitar que se siga dando el contexto violatorio de los derechos. Están dentro de las medidas de no repetición la capacitación de funcionarios públicos y la adecuación de la normativa interna del Estado condenado a los parámetros establecidos en la Convención o que se desprenden de ella.

Esta alternativa, la de tener prevista la formulación de reparaciones que pueden incluir diversos aspectos, cuenta sin duda con una serie de ventajas. En términos de la configuración de un Derecho común, ayuda contar con una resolución que especifica todos sus extremos, pues así no existe margen de error frente a lo que se quiere obtener, y quedan plenamente explicitados los alcances que se les da a las disposiciones de la Convención, así como la convencionalidad o no convencionalidad de una norma o una situación en particular. Ahora bien, justo es anotar que, precisamente por la diversidad de aspectos que dentro de este modelo puede incluir una resolución de la Corte, su cumplimiento también puede tener algunas dificultades.

$Y$ es que bien puede alegarse que en varios casos las medidas planteadas no son fáciles 
Cuando el juez(a) constitucional latinoamericano(a) olvida su labor de Convencionalización del Derecho: reflexiones en torno a una reciente sentencia de la Corte Suprema de Justicia de la Nación argentina When the Latin American constitutional judge forgets his/her job of conventionalization of law: reflections about a recent sentence of the Argentine Supreme Court of Justice.

de cumplir, ya sea por motivos fácticos (no es fácil ubicar restos humanos perdidos durante largo tiempo, por ejemplo), o por consideraciones políticas o sociales internas que pueden generarse en mérito a lo resuelto en algún caso en particular (por creerse que, con razón o sin ella, lo resuelto por la Corte puede producir eventuales y hasta poco deseables fricciones).

No puede aquí negarse la validez de estas aseveraciones en algunos casos. Sin embargo, ello tiene más que ver con la prudencia y la previsión de consecuencias de los juzgadores(as) a la hora de resolver. También puede recurrirse, como nos permitimos sugerir al actual presidente de la Corte Interamericana, el establecimiento de grupos de trabajo destinados a facilitar el establecimiento de prioridades ante aquellos escenarios de reiterado incumplimiento de lo ya exigido. $Y$ es que justo es anotar que muchas de las alegaciones, formuladas por parte de los Estados para no honrar lo comprometido con la Corte no cuentan con asidero suficiente, buscando con ello más bien eludir el cumplimiento de obligaciones ya asumidas, aunque, justo es también anotarlo, no es así en todos los casos.

\section{4 ¿Audiencias y sentencias de seguimiento o de} apreciación de los Estados como alternativa más favorable para la consolidación de un Derecho común? La evolución de lo inicialmente previsto, y el debate hoy existente sobre el tema que ahora venimos analizando dentro del Sistema Interamericano ha sido, como bien puede apreciarse, muy dinámico e importante. Esta preocupación ha sido además desarrollada en un contexto en donde la Corte interamericana, buscando asegurar el cumplimiento de sus sentencias, ha pasado a indicar a los Estados que es lo que deben hacer para reparar el daño causado a la(s) víctima(s), dejando así muy poco margen de acción para una eventual intervención estatal en un sentido distinto.

En lo expuesto, como bien puede comprobarse, no existe coincidencia con lo previsto para las sentencias del Tribunal de Estrasburgo, a las cuales puede calificárselas como obligatorias más no ejecutivas, y, por ende, con una efectividad en su ejecución que no se respalda en que ese Tribunal cuente con un sistema de ejecución forzosa de sus decisiones, sino en las condiciones internas que cada Estado establezca al respecto, contando con libertad para determinar cómo cumple con el fallo del Tribunal y cómo repara a la víctima ${ }^{(7)}$. Dicho con otras palabras, la Corte interamericana no solamente tiene incidencia durante el desarrollo del proceso que debe tramitar, sino también participa directamente en la fase de ejecución de lo que resuelve.

Esta particular perspectiva manejada por la Corte le ha llevado a construir una dinámica de supervisión de sus propias sentencias, puesta en vigencia desde el 1 de junio de 2001 frente a cinco pronunciamientos suyos en los cuales se había condenado al Estado peruano, los cuales eran a saber Castillo Páez, Loayza Tamayo, Castillo Petruzzi y otros, Baruch Ivcher y Tribunal Constitucional. Como era de esperarse, la Corte ha buscado justificar el desarrollo de esta competencia. Para ello, de un lado, ha alegado realizar una interpretación sistemática de varios preceptos de la Convención, ya que no existe en el Pacto de San José artículo alguno que expresamente le asigne a la Corte la posibilidad de supervisar el cumplimiento de sus sentencias; y de otro, ha apelado a la naturaleza de los casos que en ese momento debía resolver este importante colegiado.

Explico ahora con algo más de detalle los alcances de estas últimas afirmaciones: y es que en primer término, y ante la ausencia de artículos que expresamente le otorguen esa competencia, la Corte Interamericana ha justificado su actuación en la invocación (por separado o en conjunto) de lo dispuesto en diversas disposiciones de la Convención,

(7) Una buena síntesis sobre las diferencias existentes al respecto, es la de Susana Mosquera Monelos. Perú ante el Sistema interamericano de protección de los Derechos Humanos. La difícil combinación entre la defensa de los intereses del Estado y los estándares internacionales de protección de Derechos Humanos. Núñez, El margen de apreciación en el sistema interamericano de Derechos Humanos: proyecciones regionales y nacionales, 339 y siguientes. 


\section{Eloy Espinosa-Saldaña Barrera}

entre las cuales destacan el reconocimiento de su carácter de órgano protector de los Derechos Humanos (artículo 33), su competencia obligatoria general (artículo 62.1), su competencia especial para interpretar y aplicar la Convención (artículo 62.3), y, sobre todo, en su responsabilidad de presentar a la Asamblea General de la Organización de Estados Americanos un informe en el cual debe señalar los casos en los cuales un Estado no ha dado cumplimiento a sus fallos (artículo 65).

Ahora bien, ésta es indudablemente parte importante de la sustentación de la competencia supervisora que se ha autoatribuido este alto Tribunal, más no resulta el único elemento a tomar en cuenta. También se ha justificado la postura asumida en el tipo de controversias que, hasta el año 2001, e incluso hasta hoy, mayoritariamente le ha tocado conocer y resolver a la Corte Interamericana, en donde se han visto situaciones en las cuales la gravedad de las violaciones en que habían incurrido algunos Estados aconsejaba que esta Corte (normativamente facultada para hacerlo) regule de manera detallada y exhaustiva todo lo que debe hacerse para así poder reparar el daño ocasionado.

Así es como se ha configurado y sustentado un mecanismo de supervisión de sentencias, con convocatoria a audiencias a los Estados, para así asegurarse si éstos han cumplido con la sentencia (llamada hoy también sentencia de reparaciones y costas) en la cual han sido condenados, y la emisión de sentencias de supervisión o de cumplimiento, requiriéndose en varias oportunidades más de una sentencia de cumplimiento por caso resuelto. Hasta ahora la Corte ha recurrido a este mecanismo de supervisión de sentencias en más o menos trescientos casos, siendo alrededor de setenta vinculados a fallos contra el Estado peruano, fallos emitidos en función a hechos ocurridos en las décadas de los ochenta y noventa del siglo pasado. Ahora bien, este gran poder de la Corte ha generado muchas preocupaciones en diversos sectores. Para atenderlas, ya desde el mismo sistema Interamericano se han venido dando algunas respuestas.

Es pues en este contexto donde adquiere especial relevancia un mecanismo utilizado en el sistema interamericano, el destinado a que la Corte, a pedido del Estado que fue emplazado y recibió en un algún proceso un pronunciamiento de ese alto Tribunal, emita una sentencia de interpretación de los alcances de sus propios fallos. Bien se ha señalado que, en un escenario en donde la incidencia de la Corte es a todas luces muy fuerte, lo que viene buscando el Estado, cuando solicita se dicte una de estas sentencias de interpretación, es una modulación del pronunciamiento ya emitido, una adaptación del mismo a sus propias reglas de Derecho interno, y, justo es anotarlo, la reducción del monto de lo que debe indemnizar ${ }^{(8)}$ (tema de especial relevancia para los Estados, por las connotaciones económicas e incluso políticas que involucran estas indemnizaciones que, como bien se conoce, no se quedan en el otorgamiento de sumas de dinero a las víctimas o a sus beneficiarios).

Debe aquí tenerse presente que en estos casos estamos ante una regla de aplicación del Derecho, vinculada al margen con que cuentan las autoridades estatales para adaptar las obligaciones internacionalmente establecidas o explicitadas a su propia realidad; y no frente a una regla de interpretación o para la interpretación de lo resuelto, alternativa más bien relacionada con un ámbito de flexibilidad normativa, una zona o espacio dentro del cual los Estados cuentan con libertad de acción para limitar el ejercicio de los derechos de sus ciudadanos sin que puedan ser sancionados por ello. Un buen ejemplo de esta posible modulación o flexibilización, con todos sus riesgos, son las previsiones de la Ley peruana 27775 , materia a la cual nos hemos referido en otros trabajos.

Sin desmerecer entonces la importancia de todas estas construcciones jurisprudenciales y doctrinarias, así como de su apoyo normativo,

(8) Véase Núñez, El margen de apreciación en el sistema interamericano de Derechos Humanos: proyecciones regionales y nacionales, 341-342. 
Cuando el juez(a) constitucional latinoamericano(a) olvida su labor de Convencionalización del Derecho: reflexiones en torno a una reciente sentencia de la Corte Suprema de Justicia de la Nación argentina When the Latin American constitutional judge forgets his/her job of conventionalization of law: reflections about a recent sentence of the Argentine Supreme Court of Justice.

también es necesario anotar que, en tanto y cuanto muchas veces es posible encontrar una pluralidad de valoraciones en materia de derechos, muchos consideran necesario asegurar que los órganos internacionales o supranacionales no puedan en todos los casos descartar sin más comprensiones distintas a las suyas, comprensiones basadas en una valoración de ciertas particulares circunstancias que permitirían configurar una versión o entendimiento local de los derechos involucrados. Estas apreciaciones, junto a otras similares, son las que han permitido en Europa pasar a la configuración de la doctrina del margen de apreciación de los Estados.

Necesario es anotar que la conformación de esta doctrina ha tenido críticas y críticos en el mismo contexto europeo. Así, García Roca, entre otros importantes autores, ha destacado el origen poco claro de la misma; la ausencia de mención y debate sobre sus alcances en los trabajos preparatorios de la normativa que hoy compone el sistema Europeo; su débil configuración, la cual permite aplicaciones variadas y hasta contradictorias de lo que puede abarcar, así como una discrecionalidad en su comprensión que ya linda con la arbitrariedad; o la falta de sistematización de sus diferentes componentes $^{(9)}$. Coincidiendo en que dicha doctrina tiene todas estas debilidades, y por ende, que resulta más confiable recurrir a alternativas como las audiencias y sentencias de seguimiento o cumplimiento, cierto es también que el margen de apreciación de los Estados no solamente ha sido invocada en reiteradas oportunidades en el sistema Europeo, sino que hoy algunos abogan por su aplicación en el sistema interamericano, y otros inclusive hacen referencia a casos donde su materialización ya se habría realizado.
Para que puedan tenerse suficientes elementos de juicio sobre la pertinencia de invocar esta doctrina en el sistema Interamericano (con su consiguiente aplicación por Estados como el peruano) conviene entonces presentar siquiera puntualmente los alcances de dicha postura doctrinaria. En ese contexto, primero cabe señalar que el margen de apreciación de los Estados, tanto en su faceta sustantiva como en la estructural ${ }^{(10)}$, tiende a identificarse como el ámbito de deferencia que los órganos internacionales debieran reconocer a las entidades legislativas judiciales y administrativas nacionales, para que así estas últimas puedan cumplir con las obligaciones que se derivan de los instrumentos internacionales de Derechos humanos ${ }^{(11)}$.

Lo recientemente expuesto implica dar en Europa un margen de acción a los Estados para, por citar los casos más frecuentes, dichos Estados puedan apreciar las circunstancias materiales que ameritan la aplicación de medidas excepcionales en situaciones de emergencia; limitar el ejercicio de algunos de los derechos reconocidos en los instrumentos internacionales, con el objeto de resguardar otros derechos o los intereses de la comunidad; o definir el contenido de los derechos y determinar el modo en que estos

(9) Véase al respecto, Javier García Roca, "La muy discrecional doctrina del margen de apreciación nacional según el Tribunal Europeo de Derechos Humanos", Teoría y Realidad Constitucional, 20 (2007) 117 y siguientes. Es más, y como anota el mismo García Roca en otro de sus trabajos, la misma naturaleza procesal del margen de apreciación de los Estados n es clara, acercándose más bien a un principio ordenador del proceso (con un alcance material y no formal), un argumento consustancial de cuyos derechos contenidos en el tratado internacional. Véase al respecto Javier García Roca, El margen de apreciación en la interpretación del Convenio Europeo de Derechos Humanos; entre soberanía e integración. (Navarra: Civitas-Thomson, 2010), 219-244.

(10) Se hace aquí referencia a denominaciones explicadas entre otros por Letsas. La faceta sustantiva de esta doctrina está vinculada a constatar la necesidad de un discernimiento entre libertades individuales y objetivos colectivos. Su faceta estructural se encuentra relacionada con la intensidad del escrutinio de los Tribunales internacionales sobre la actividad de los órganos nacionales. Conviene revisar entonces, George Letsas, A Theory of Interpretation of the European Conventions of Human Rights. (Oxford: Oxford University Press, 2007), 80 y siguientes.

(11) Núñez, El margen de apreciación en el sistema interamericano de Derechos Humanos: proyecciones regionales y nacionales, 5 . 


\section{Eloy Espinosa-Saldaña Barrera}

derechos se desarrollan en el ordenamiento interno de su Estado en particular. Incluso los defensores del margen de apreciación estatal suelen decir que la misma facilitaría la actuación estatal en la determinación del sentido del Derecho nacional y en la definición del modo en que se cumplirá una resolución emitida por un órgano internacional responsable de la supervisión de un tratado.

Bajo estos parámetros es que encontramos un frecuente uso del margen de apreciación de los Estados en la jurisprudencia del Tribunal Europeo de Derechos Humanos, aunque con especial incidencia en temas como el de revisión de medidas relacionadas a derechos como la libertad y seguridad individual (recogidos en el artículo 5 del Convenio Europeo); el debido proceso (artículo 6); la intimidad (artículo 8); la libertad de pensamiento, conciencia y religión (artículo 9); la libertad de expresión (artículo 10); o las libertades de asociación y reunión (artículo 11).

También el margen de apreciación es invocado si de lo que se trata es de fijar los alcances de la cláusula de no discriminación (igualdad) del artículo 14 del Convenio; o de determinar las repercusiones que pueden tener sobre el ejercicio de los diversos derechos la declaratoria y vigencia de un Estado de Emergencia conforme al artículo 15 del Convenio.

Justo es anotar como también en la jurisprudencia del Tribunal de Justicia de la Unión Europea puede encontrarse la aplicación de pautas que cabe entender como muy cercanas al margen de apreciación.

En ese sentido se encuentran, por solamente citar unos casos, donde el ya antiguo Henn y Darby (1979), varios otros, entre los cuales bien puede destacarse a Sindar (1999); Haim (2000); Ferring (2002); Schmidberger (2003); Omega (2004) o Karner (2004).

Se cuenta entonces ya con algunos elementos de juicio para responder si corresponde invocar y aplicar la doctrina del margen de apreciación de los Estados en un contexto como el del Sistema Interamericano. Debe aquí anotarse como algunos autores rechazan la conveniencia de su aplicación en el Sistema interamericano y hasta se felicitan del poco desarrollo de esta posición en nuestros países ${ }^{(12)}$; y otros, partiendo de anotar que no se trata de una doctrina expresamente recogida en la Convención Americana, concluyen que el margen de apreciación no debería invocar o solamente debería ser invocado con mucha precaución ${ }^{(13)}$.

Ahora bien, cierto es que en el sistema interamericano puede, incluso a nivel de admisibilidad de los casos, encontrarse pronunciamientos cuyo sustento bien podría involucrar una aplicación de consideraciones por lo menos similares a las que en Europa han permitido sustentar la doctrina del margen de apreciación de los Estados. Ello podría decirse de lo resuelto, sobre todo en materias tan sensibles como las de la restricción de visitas íntimas alegándose intolerancia frente a la homosexualidad (caso Álvarez Giraldo, de 1999); las técnicas de fertilización artificial (caso Sánchez Villalobos, de 2004); y la pornografía y la protección de los menores y la moral pública mediante prácticas que muchos denominan de censura de revistas (caso Chávez Carbonero, de 2005).

Debe asimismo tenerse presente que muchos ya alegan se ha dado la aplicación del margen de apreciación de los Estados en nuestro Sistema Interamericano en función a lo resuelto en el caso Efraín Ríos Montt (1993); y se discute la pertinencia de su invocación en casos ante la Comisión como,

(12) En ese sentido, entre otros, Antonio Cancado Trindade. El Derecho Internacional de los Derechos Humanos en el siglo XXI. 2da.ed. (Santiago: Editorial Jurídica de Chile 2006), 389 y siguientes. Básicamente los detractores de esta postura alegan que la misma facilitaría que nuestros Estados incumplan lo previsto por la Corte y lo recogido en la convención y demás instrumentos de protección de derechos propios del Sistema interamericano.

(13) En esa línea se encuentra, por ejemplo, Héctor Faundez. El sistema Interamericano de protección de los Derechos Humanos. Aspectos institucionales y procesales. $3^{\mathrm{a}}$ ed. (San José: Instituto Iberoamericano de Derechos Humanos, 2004), sobre todo página 57. 
Cuando el juez(a) constitucional latinoamericano(a) olvida su labor de Convencionalización del Derecho: reflexiones en torno a una reciente sentencia de la Corte Suprema de Justicia de la Nación argentina When the Latin American constitutional judge forgets his/her job of conventionalization of law: reflections about a recent sentence of the Argentine Supreme Court of Justice.

entre otros el Cristian White y Garry Potter (por Baby Boy) de 1981; Statehood Roach y Jay Pinkerton vs. Estados Unidos (1987); Bomchil y Ferraro (1988); Andrés Aylwin y otros vs. Chile (1999); Vásquez Vejarano vs. Perú (2000); o Solidarity Comnitte vs. Estados Unidos (2003).

Puede además agregarse que, como señalan los defensores de la inclusión de esta doctrina en el Sistema interamericano ${ }^{(14)}$, ya existirían hasta seis espacios en la jurisprudencia de la Corte interamericana en donde de cierta forma la Corte habría aplicado esta polémica doctrina. Estos espacios o ejes serían a saber los siguientes:

a) El del desarrollo normativo interno de los derechos reconocidos en la Convención Americana de Derechos Humanos (en ese sentido se alega estaría lo resuelto en la Opinión consultiva dieciocho, del año 2003; y la sentencia emitida en Herrera Ulloa vs. Costa Rica el año 2004).

b) La configuración de las instituciones nacionales que inciden en el desarrollo o el ejercicio de los derechos reconocidos en la Convención (en ese tenor se considera estarían la Opinión Consultiva 4, del año 1984; y el caso Castañeda Gutman vs México, del año 2008).

c) La valoración de las circunstancias materiales que justifican la limitación de los derechos reconocidos en la Convención (en esa línea estaría, según los promotores de esta postura, el caso Chaparro Alvarez y Lapo Iñiguez vs. Ecuador, del año 2007).

d) La regulación de los derechos no reconocidos en la Convención (se alega que ese sería el razonamiento seguido en los casos Dacosta Cadogan vs. Barbados, del año 2009; o Atala y Niñas vs.Chile, del año 2012).

e) El alcance de la competencia jurisdiccional de la Corte en los casos contenciosos (en esa pauta se considera que estaría el aquí ya citado Chaparro Álvarez y Lapo Iñiguez vs. Ecuador, del año 2007).

f) El cumplimiento de las sentencias (en ese sentido se argumenta que se encontraría la resolución del 29 de junio de 2005, sobre supervisión de cumplimiento de sentencias, entre otros múltiples pronunciamientos de la Corte.

Ahora bien, y aun asumiendo la existencia de los elementos de juicio señalados por los propulsores de la aplicación de la doctrina del margen de apreciación de los Estados en el Sistema Interamericano, resulta también necesario anotar cual es el sustento de las ostensibles resistencias existentes en nuestra Corte de San José para aceptar lo que es una consecuencia lógica de la aplicación de esta doctrina. $Y$ es que la admisión de que, en determinadas circunstancias, las autoridades nacionales pueden definir mejor si una actividad efectuada o una normativa vigente en sus respectivos Estados es o no conforme con lo recogido en la Convención Americana de Derechos Humanos, puede involucrar dejar abierta la puerta para un sistemático incumplimiento de parámetros convencionales, y conspirar así contra la consolidación de un Derecho común conforme a los derechos.

Ese es pues un posible escenario que en el contexto de nuestros países es resistido, y también es fuertemente objetado en el caso europeo, pues permite que, bajo consideraciones muy subjetivas e imprecisas, un Estado pueda asumir posiciones poco tuitivas de los derechos ciudadanos. Si lo que se quiere es consolidar la tutela de los derechos, y máxime dentro de una lógica de Derecho común, resulta sensato dejar de lado la aplicación del margen de apreciación estatal y optar (por lo menos a falta de una alternativa mejor) por la alternativa asumida en el Sistema Interamericano (sentencias y audiencias de seguimiento o cumplimiento), máxime se toma en cuenta el carácter de las sentencias que aquí se emiten.

(14) Núñez, El margen de apreciación en el sistema interamericano de Derechos Humanos: proyecciones regionales y nacionales, 22. 
Eloy Espinosa-Saldaña Barrera

Son pues estos los instrumentos con los que cuenta el Sistema Interamericano para hacer cumplir sus fallos, y apuntalar la construcción de un Derecho común. Veremos entonces ahora como todos esos elementos han actuado en su práctica más bien cotidiana, y si han permitido abstener tal loables objetivos.

\section{Sobre la relevancia de la convencionalización del Derecho en un contexto como el latinoamericano}

Como ya se ha dicho incluso en este mismo texto, una de las más importantes tareas a cargo de un juez o jueza constitucional es hoy, qué duda cabe, la de la convencionalización del Derecho. $Y$ es que, sobre todo en contextos como el latinoamericano, en donde problemas a nivel mundial (crisis de respeto a los derechos, muy a despecho de su reconocimiento constitucional, legal o jurisprudencial; crisis por falta o por insuficiencia de reconocimiento y vigencia de la idea de buen gobierno, etcétera) se dan la mano con algunas limitaciones ya casi endémicas en nuestros países, la convencionalización del Derecho ha sido, indudablemente, un importante elemento para proteger los derechos de las diferentes personas, y a la vez, para democratizar el ejercicio del poder que desempeñan las autoridades involucradas en esta dinámica.

No se puede dejar de tomar en cuenta como en un escenario como el latinoamericano, además de lo que se encuentra a nivel mundial, nos encontramos, entre otros elementos planteados con mayor o menor intensidad en función a la condición de cada Estado en particular, ante la constatación de una situación de debilidad institucional y de poca participación ciudadana en la toma de las decisiones más relevantes en una sociedad determinada. Junto a ello conviene anotar que el quehacer político estatal latinoamericano oscila entre democracias insuficientes (ubicadas entre los riesgos de democracias elitistas excluyentes ${ }^{(15)}$ y diversas manifestaciones de populismo(16) y autocracias más o menos desembozadas.

Y por si lo expuesto no fuera suficiente, si bien son importantes los logros tuitivos alcanzados básicamente en el ámbito de los derechos, necesario es anotar como muchas veces existe un reconocimiento más formal que real de algunos derechos, o nos encontramos ante situaciones donde la titularidad de ciertos derechos aparece como razonablemente restringido para ciertos colectivos. También hay cuestionamientos vinculados con la actuación de quienes desempeñan labores jurisdiccionales, como los referidos al carácter contramayoritario de la tarea jurisdiccional, la legitimidad democrática de la labor emprendida, o la falta de familiaridad con las particularidades de la interpretación constitucional (riesgo de encontrarnos con interpretaciones hiperformalistas, o de ubicarnos ante comprensiones que demuestran serias deficiencias formativas a nivel argumentativo en el plano conceptual).

Incluso son cuestionables algunas disposiciones constitucionales o ciertas regulaciones o prácticas vinculadas con competencias asignadas a los juzgadores (sistemas de nombramiento, promoción, sanción y término de la carrera de juezas o jueces, o manejo de recursos económicos); $y$, finalmente, la hiperreglamentación de los derechos recogida en algunas Constituciones, la cual, por cierto, con intención o sin ella,

(15) Nombre que se otorga a posturas como las acogidas en su momento por Schumpeter, las cuales el antecedente de posturas como las de la escuela del Public Choice, hoy predominantemente en la Ciencia Política norteamericana. Una estupenda explicación de los alcances y consecuencias de este elitismo excluyente lo encontramos en, Pedro Salazar Ugarte. Política y Derecho (Derecho y Garantías). Cinco ensayos latinoamericanos. (México: Fontamara, 2013), 34 y siguientes.

(16) Y es que en América Latina, más no solamente allí, se ha tenido y se tiene manifestaciones del populismo que puedan ser definidas de derecha (invocan representatividad popular adscrita a perspectivas de fortalecimiento del status quo ante) o de izquierda (se reivindica un cambio del status del quo ante y de las correlaciones del poder desde una perspectiva que se reclama progresista pero que, o mantiene la misma concentración del poder a otras manos pero, en el fondo, bajo las mismas prácticas). 
Cuando el juez(a) constitucional latinoamericano(a) olvida su labor de Convencionalización del Derecho: reflexiones en torno a una reciente sentencia de la Corte Suprema de Justicia de la Nación argentina When the Latin American constitutional judge forgets his/her job of conventionalization of law: reflections about a recent sentence of the Argentine Supreme Court of Justice.

recorta el ámbito de acción de quienes juzgan o interpretan. Frente a este contexto, adquiere innegable relevancia el aporte de la ya mencionada convencionalización del Derecho.

Sinceramente creo que hay mucho a favor de la relevancia y utilidad de la convencionalización del Derecho frente a la labor que hoy tocó asumir a jueces y juezas. En primer lugar, se apuesta por la configuración de un Derecho común permite, desde la diversidad, construir o rescatar lo propio (que, por cierto, no es excluyente o peyorativo de lo distinto). En este sentido, facilita acoger y sistematizar aportes de la normativa y jurisprudencia de nuestros países, así como las buenas prácticas allí existentes, elementos de vital relevancia para enriquecer el quehacer jurisdiccional. Conviene entonces aquí resaltar que la convencionalización del Derecho no implica la desaparición o el desconocimiento de lo propio. Implica más bien su comprensión dentro de un escenario de diálogo multinivel, para así enriquecerlo y potenciarlo.

En segundo término, la convencionalización del Derecho facilita una comprensión de los temas en la cual cuando a nivel interno no ha habido respuesta a alguna materia (o dicha respuesta ha sido deficitaria en términos de reconocimiento y protección de derechos), permite recurrir a una pauta para la configuración de una alternativa, pauta proveniente del texto de las convencionales suscritas por cada Estado, la interpretación vinculante de las mismas o aquello que hoy se nos presenta como normas de lus Cogens (sin que ello, claro está, involucre reconocer la relevancia de lo propio, si existe, como elemento central para la configuración o el enriquecimiento, -según fuese el caso- de un parámetro común).

De otro lado, y en tanto y en cuanto parte de una idea de la interpretación de la Constitución y del Derecho como concretización, la dinámica aquí descrita le permite al juez(a) constitucional desarrollar una perspectiva de su labor a la cual podemos calificar como principalista, o sustentada en la materialización de ciertos principios. Ellos posibilita a los juzgadores(as) contar con una compresión dinámica de su labor, comprensión no cerrada a una sola manera de entender las cosas para enfrentar los diferentes problemas existentes, problemas ante los cuales cada vez se le pide más una respuesta pronta y certera de estos juzgadores.

No debe además soslayarse que, muy a diferencia de lo que sucede con otras construcciones, donde la alegación de estar trabajando por buscar superar las limitaciones de un contexto de democracia formal o insuficiente muchas veces parece más ben encerrar la justificación de nuevas expresiones de un populismo bastante lejano al ideal que se dice querer propulsar, la convencionalización del Derecho parte de una clara defensa de aquello que inspira, orienta y regula (muy a despecho de innegables tensiones y dificultades) el quehacer de un Estado Constitucional y Democrático.

En ese sentido, esta dinámica ayuda a quienes interpretan y hasta juzgan, a encontrar o generar respuestas debidamente articuladas con los parámetros que por lo menos hoy acompañan al Estado Constitucional y la democracia constitucional. Con esto me estoy refiriendo a que permite construir, o por lo menos, potenciar opciones en donde se imponen límites y vínculos constitucionales de las decisiones de los órganos de gobierno democráticos. Ello con el objetivo de preservar el rol de los derechos fundamentales como centro no solamente de la acción estatal, sino del quehacer de todo aquel que cuenta con autoridad.

Entonces, y a modo de síntesis, bien puede señalarse que en un escenario tan complejo como el que toca enfrentar a los jueces y juezas, la apuesta por un Derecho Común deviene en un poderoso aliado para la configuración, el enriquecimiento y la validación de las respuestas a dar a determinados y graves problemas. Necesario es entonces anotar aquí que, y ya frente a estas materias, ha habido importantes avances construidos o potenciados desde sede jurisdiccional.

Para ello se ha seguido, explícita o inconscientemente pautas como las reseñadas en este texto. Hay pues relevantes e innegables aportes en ese sentido. Sin embargo, tampoco puede soslayarse la subsistencia de significativos retos por enfrentar. Precisamente 
Eloy Espinosa-Saldaña Barrera

sobre estos aspectos pasaré a efectuar, siquiera a modo de puntual reseña, alguna referencia de inmediato.

\section{Los retos a enfrentar para la consolidación de la convencionalización del derecho a nivel jurisdiccional en América Latina}

En una época donde la labor de interpretación y resolución de conflictos en sede jurisdiccional se ha potenciado decididamente, muy a despecho de eventuales cuestionamientos, es innegable reconocer como el quehacer jurisprudencial ha planteado importantes avances en esta misma dirección. Estos avances, por cierto, no se han quedado en el ámbito de tutela de los derechos, sino que se han proyectado también al escenario de la toma de las decisiones de gobierno y gestión más relevantes en un Estado en particular ${ }^{(17)}$.

Ahora bien, estos avances o aportes deben también, en su caso, hacer frente a la presencia de algunos significativos retos, más allá de los problemas de contexto mundial y latinoamericano a los cuales he hecho mención en otra parte de este mismo texto. Mucho es lo que podría decirse al respecto, pero aquí, siquiera puntualmente, voy a referirme a tres temas que considero son de la mayor importancia. El primero de ellos va dirigido a discutir qué y con cuál legitimidad algo es justiciable. El segundo, muy directamente relacionada con lo anterior, se vincula a sí, por la particular configuración del quehacer jurisdiccional, todo es realmente justiciable. El tercero va referido a la comprensión de los alcances de la misma tarea de convencionalización asumida. Buscar proporcionar insumos acerca de cómo abordar estos temas es aquello a lo cual dirigiré mi atención a continuación.

\subsection{EI reto sobre qué es justiciable y sobre con cuál legitimidad algo lo es}

No olvidemos que es parte de la premisa mediante la cual se afirma que un Estado Constitucional no deben existir zonas o actividades exentas de control, y que la lucha para evitar la inmunidad (que suele devenir en impunidad) en el ejercicio del poder no debe detenerse. También demos tener presente que el Estado Constitucional se caracteriza por ser un Estado limitado, donde nadie tiene todo el poder, sino cuotas del mismo (competencias), las cuales son expresamente asignadas a cada quien en la Constitución, o en su caso, por la norma correspondiente dictada por la autoridad competente, o por lo que se desprenda razonablemente de esa normativa, aunque allí no se encuentre explícitamente señalada.

Además, en el Estado Constitucional no solamente importa contar con la competencia para desempeñar una función (incluso la de interpretación vinculante y control de constitucionalidad). Importa también llegar a esa responsabilidad y ejercerla dentro de ciertos parámetros. Por ende, un juez o una jueza constitucional tienen tareas muy importantes a su cargo, pero no están habilitadas para hacerlo todo. Corresponde entonces siempre preguntarse no solamente por la legitimidad de su labor, así como de un tema muy vinculado con éste, el de los límites del quehacer de un juez o jueza constitucional.

Mucho se ha dicho sobre la legitimidad del quehacer jurisdiccional, y con más detalle se ha hablado de la legitimidad de la labor de jueces y juezas constitucionales. Aún cuando el tema no se encuentra exento de polémica, en líneas generales se parte de reconocer que la Constitución es una norma jurídica con proyecciones para regular no solamente el quehacer jurídico, sino también el político, el social y el cultural. La interpretación de

(17) Una explicación sobre los importantes avances alcanzados al respecto se encuentra en "Los retos de un(a) juez o juez(a) constitucional en un contexto de crisis y el aporte de la Convencionalización del Derecho en esta labor jurisdiccional". En: Libro Homenaje a Lucio Pegoraro (en prensa, 2011). También abordó el tema en Derecho y Debate 27 (diciembre de 2016), www.derechoydebate.com 
Cuando el juez(a) constitucional latinoamericano(a) olvida su labor de Convencionalización del Derecho: reflexiones en torno a una reciente sentencia de la Corte Suprema de Justicia de la Nación argentina When the Latin American constitutional judge forgets his/her job of conventionalization of law: reflections about a recent sentence of the Argentine Supreme Court of Justice.

dicha Constitución no solamente busca tutelar la voluntad general, sino sobre todo una mejor protección de los derechos (y especialmente los de las minorías), garantizado ello con una limitación del poder que se traduce en la distribución de funciones y de mecanismos de control a esas funciones.

El juez o jueza constitucional se legitima en esa delicada labor en función a que asume y justifica sus competencias en mérito a parámetros establecidos conforme a Derecho, en la imparcialidad que debe caracterizar a su quehacer jurisdiccional, y al desarrollo de sus tareas en base a su conocimiento del Derecho y lo jurídico (que es precisamente lo que debe aplicar). Ahora bien, justo es anotar que muchas veces estos argumentos son más fáciles de formular que de materializar.

Es importante entonces aquí tener presente el tema de los límites a la labor del juez o jueza constitucional. Conviene entender que el quehacer de estos juzgadores y juzgadoras tiene un punto de partida y por ende, un límite: la Constitución (más que en su lectura literal, en su comprensión sistemática o convencionalizada) y lo que puede inferirse razonablemente de lo previsto en ella. También debe comprenderse que estamos ante autoridades, y por ende, frente a personas que en las tareas a su cargo deben respetar parámetros de racionalidad, razonabilidad, corrección funcional o deber de motivación.

Por último, y en tanto y en cuanto son autoridades con labores de carácter jurisdiccional, no corresponde a esos jueces y juezas efectuar juicios en base a consideraciones de calidad o de oportunidad. En estos casos también operan como límites al quehacer del juez los alcances de las pretensiones puestas en su conocimiento, frente a las cuales puedan actuar en aplicación del lura Novit Curiae o de la suplencia de queja deficiente, más no romper una indispensable congruencia funcional; la especialidad de las materias decididas; la misma convencionalización del Derecho, pues deja de lado y sin sustento algunas posibilidades interpretativas para los diferentes juzgadores y juzgadoras; $y$, finalmente, por no seguir con un largo etcétera, cuenta también la complejidad de los casos puestos en conocimiento de una jueza o juez (fáciles, intermedios, difíciles y hasta trágicos ${ }^{(18)}$ ) como elemento a tomar en cuenta para limitar su accionar.
Sin embargo, no son estas materias las únicas que generan algunas interrogantes. Cabe también preguntarse, tomando en cuenta las especiales características de ciertos temas, si es posible que puedan ejercerse sobre ellas eficientemente las labores de interpretación y control que se le piden a los jueces y juezas. Cabe entonces cuestionarse por si realmente todo es justiciable. En el fondo de ello hay una pregunta clave dentro del Estado Constitucional, uno de cuyos aspectos básicos es el de la necesidad de limitar y organizar el poder: la pregunta sobre quién se encarga de qué en un Estado, así como en una sociedad en particular. Corresponde entonces pasar a dar algunos apuntes al respecto.

\subsection{El reto sobre si todo es realmente justiciable.}

Centraré el análisis en un tema en particular a modo de ejemplo de lo que queremos plantear: el electoral. ¿Acaso todo lo conflictivo en lo electoral (materia sobre cuyos alcances por cierto no necesariamente coincide el análisis de todos) es canalizable en sede jurisdiccional? La dificultad de lo que debe resolverse en tan poco tiempo, la real utilidad de la labor de algunas autoridades electorales, en función a sus actuales configuraciones y diseños o el riesgo de politización de los espacios jurisdiccionales específicamente previstos para atender lo electoral (o que deben efectuar una interpretación constitucional con competencia en lo electoral) son algunos de los factores que por lo menos ponen en entredicho la pertinencia de judicializar cualquier materia, aún cuando dicha judicialización sea confiada a jueces y juezas constitucionales.

Bien podrá resaltarse la especial sensibilidad que genera el tema electoral, en donde se encuentra en juego precisamente como alguien llega o se mantiene en el ejercicio de los

(18) En este sentido conviene revisar el importante trabajo de Manuel Atienza, "Los límites de la interpretación constitucional. De nuevo sobre los casos trágicos," Isonomía 6 (1997). 


\section{Eloy Espinosa-Saldaña Barrera}

espacios que habilitan a un ejercicio legitimado de las mayores cuotas de poder en un Estado o en una sociedad en particular. $Y$ es que confiar a políticos el control del quehacer político puede sin duda causar ciertos resquemores. Sin embargo, y como acertadamente plantea Diego Valadés, existen casos ante los cuales las garantías de carácter jurisdiccional devienen en francamente ineficientes, siendo oportuno analizar la conveniencia de recurrir en estos casos a lo que el reconocido jurista mexicano denomina garantía política ${ }^{(19)}$.

Como fácilmente puede apreciarse, la misma pertinencia de acudir al escenario jurisdiccional es lo que muchas veces se encuentra cuestionada. Ante la dificultad de dar respuesta a tan difíciles materias, y mirando los temas desde una perspectiva positiva, adquiere entonces especial significación contar con perspectivas interpretativas como la de la convencionalización del Derecho para así preservar o potenciar aspectos tan relevantes como aquellos a los cuales he hecho mención en otros apartados de este texto, muy a despecho de si eventualmente la aplicación de esta propuesta es o no finalmente confiada a organismos de naturaleza jurisdiccional.

\subsection{El reto sobre la comprensión de los alcances de las tareas de convencionalización del Derecho}

Como se ha dicho en más de una ocasión, se entiende por convencionalización del Derecho a esa apuesta por la configuración de un Derecho Común (que no descuida lo propio, sino que busca potenciarlo en un escenario más tuitivo y generalizado), dentro del cual la comprensión del Derecho y de los derechos debe hablarse de acuerdo con lo señalado en los diferentes tratados suscritos por los distintos Estados, o, en su caso, conforme a lo que se desprender de dichos tratados, o de acuerdo con aquella normativa que ya ha adquirido carácter de lus Cogens.

Ahora bien, necesario es anotar que los alcances de esta convencionalización (máxime en el escenario latinoamericano, donde se ha optado por un control de convencionalidad y no por un margen de apreciación estatal; la misma Corte Interamericana apuesta por un sistema de reparaciones integrales; y, finalmente, la Corte de San José de Costa Rica ha establecido su propio sistema de audiencias y sentencias para asegurar la ejecución y el cumplimiento de sus sentencias) también han admitido lecturas distintas.

Así hay quienes hacen una lectura literal de lo previsto, por ejemplo, en la Convención de Viena sobre los tratados, y señalan sin más que no cabe alegar Derecho interno para desconocer el parámetro convencional. Frente a esta postura extrema, hay quienes alegan un carácter subsidiario de la convencionalización frente a lo existente en el Derecho interno, y sobre todo a nivel constitucional. En ese tenor, lo convencional solo se cumple si no afecta el parámetro constitucional interno, correspondiendo en principio a los organismos competentes de cada país (en líneas generales, las Altas Cortes de cada país, responsabilidad que incluso podría compartirse con otros órganos jurisdiccionales) determinar si es aplicable lo convencional o no.

Es más, hay quienes argumentan que la comprensión en clave convencional de estos temas debe entenderse en una dinámica de estándar mínimo: prima lo convencional mientras no sea que lo estatal no sea más tuitivo. Si lo previsto en un Estado en particular fuese más tuitivo que el parámetro convencional, primará la solución estatal en esa situación en particular. Esta postura es interesante, pero tiene la dificultad de determinar qué es lo más tuitivo y a quién corresponde esa determinación.

Sin embargo, corresponde entender que la configuración de la convencionalización del Derecho se da, como bien ha indicado calificada doctrina ${ }^{(20)}$, comprendiendo que hoy

(19) Véase Diego Valadés, "La garantía política como principio constitucional," Boletín Mexicano de Derecho Comparado 132. (Setiembre-diciembre 2011), 1259-1291.

(20) Véase al respecto, Calógero Pizzolo “¿Ser 'intérprete supremo' en una comunidad de intérpretes finales?,” La Ley (Febrero 2017) Año LXXXI No. 39, Tom. 2017-A. 
Cuando el juez(a) constitucional latinoamericano(a) olvida su labor de Convencionalización del Derecho: reflexiones en torno a una reciente sentencia de la Corte Suprema de Justicia de la Nación argentina When the Latin American constitutional judge forgets his/her job of conventionalization of law: reflections about a recent sentence of the Argentine Supreme Court of Justice.

nos encontramos en un escenario de fragmentación jurídica, $y$, por ende, de pluralismo interpretativo: alguien va a tener que dar la última palabra en un caso en particular, la solución de dicho caso. Ahora bien, ello no va a ser consecuencia de la decisión unilateral de un supremo intérprete sobre los eventuales pareceres de otros intérpretes que en ciertos contextos pueden ser calificados como finales.

Y es que el tantas veces invocado diálogo multinivel no implica que alguien decide y el resto acata. Involucra más bien el uso de técnicas de cohabitación para así articular unas no siempre sencillas relaciones interordinamentales. La necesaria convergencia de interpretaciones en un escenario de varios intérpretes que se reclaman como finales va a llevar a la generación de consensos mínimos que encuentran en el principio pro homine su límite de actuación ${ }^{(21)}$.

Estos consensos mínimos, como bien se ha explicado ${ }^{(22)}$, son soluciones de síntesis, centradas en evitar interferir sobre la eficacia de la norma interconectada. Alcanzar estos consensos mínimos implica articular entre la comunidad de intérpretes finales una forma específica de lenguaje que comunique a sus integrantes y, a la vez, los represente. La obtención de una respuesta común consensuada, añado ya a nivel personal, sin desconocer con ello, añado también lo ya previsto en el parámetro convencional.

Bien podría cuestionarse la relativa perdida de certeza a la cual puede llevar la construcción de este tipo de respuestas. Esto, por lo demás, no es en rigor ni nuevo ni cierto. Es lo que ya ocurre en la práctica en muchos países donde ya a nivel jurisdiccional coexisten varios intérpretes finales (o por lo menos, que reclaman esa condición), para así evitar un choque de trenes, o, dicho con otras palabras, inconvenientes y harto perjudiciales conflictos interinstitucionales.

Ahora bien, tampoco debe perderse de vista que la certeza de un pronunciamiento vinculante (entre los cuales destacan nítidamente las resoluciones emitidas por órganos con competencias jurisdiccionales) no solamente está marcada por la pulcritud de su redacción y motivación. Aquello, que sin duda es indispensablee, debe darse en un contexto en que asegure el cumplimiento de lo planteado. Eso es precisamente lo que busca conseguirse generando consensos mínimos entre la pluralidad de intérpretes vinculados.

\section{Algunas puntuales especificaciones sobre lo resuelto por la Corte Suprema frente a la sentencia emitida por la Corte Interamericana de Derechos Humanos en el caso Fontevecchia y D'Amico vs. Argentina}

Hace algunos años, cuando Carlos Menem era presidente de la Argentina, corrió el rumor que tenía un hijo al cual no reconocía públicamente. La revista Noticias investigó el hecho, y no solamente hizo una serie de notas al respecto, sino que dedico alguna tapa de esa publicación a este tema. El entonces presidente argentino demandó a la revista Noticias, planteando que dicha revista habría violado su derecho a la intimidad.

Luego de haberse rechaza la demanda en primer grado, tanto la Cámara de Apelaciones en lo Civil de la Capital Federal como la Corte Suprema de Justicia de la Nación argentina más bien proceden a condenar a la editorial que emite Noticias como a los ciudadanos Jorge Fontevecchia y Héctor D'Amico a pagar una indemnización. Este caso es llevado a la Corte Interamericana, la cual el año 2011, considera, para plantearlo aquí muy puntualmente, que en este caso la revelación hecha por Noticias estaba justificada, al ser Menem una figura pública; y que la condena aplicada en Argentina constituía una violación a la libertad de expresión. Por ello, condena al Estado argentino en este proceso en particular.

Cabe destacar que la condena al Estado argentino, en la lógica de reparación integral

(21) Calógero Pizzolo, ¿Ser "intérprete supremo" en una comunidad de intérpretes finales?

(22) Calógero Pizzolo, ¿Ser "intérprete supremo" en una comunidad de intérpretes finales? 


\section{Eloy Espinosa-Saldaña Barrera}

que aplica la Corte Interamericana de Derechos Humanos, incluía tomar las siguientes acciones:

a) Dejar sin efecto la condena impuesta a Fontevecchia y D’Amico, así como todas sus consecuencias.

b) Publicar completa la sentencia de la Corte Interamericana de Derechos Humanos en la página del Centro de Información Judicial de la Corte Suprema, así como un resumen oficial de lo resuelto por la Corte Interamericano (elaborado por la Corte Suprema) en el Diario Oficial y en un diario de amplia circulación.

c) Devolver a Fontevecchia y a D'Amico lo que habían pagado por la condena, y además, los gastos que tuvieron que hacerse durante el proceso ante la judicatura argentina.

El Estado argentino ya había cumplido con las publicaciones mencionadas en el punto dos, y estaba ya tramitando las devoluciones incluidas en el punto tres. Es en ese contexto que el Ministerio de Relaciones Exteriores le pide a la Corte Suprema de su país que cumpla con el punto uno al cual acabo de hacer mención.

Ante ese requerimiento, la Corte Suprema de Justicia de la Nación argentina, con fecha 14 de febrero de 2017, en mayoría, señala lo siguiente:

a) Si bien se reconoce que el cumplimiento de las sentencias de la Corte Interamericana es en principio obligatorio, esa obligatoriedad puede discutirse si la Corte Interamericana no cumple con ciertas condiciones, y entre ellas, ceñirse a sus propias competencias.

b) La Corte Suprema argentina se autohabilita la competencia de determinar si la Corte Interamericana, al momento de emitir "Fontevecchia y D'Amico c. Argentina", está en el ejercicio de sus atribuciones o se encuentra actuando al margen de ella. En este caso en particular, considera que la Corte Interamericana ha ido más allá de sus propias competencias.

c) Se alega que la protección internacional de los derechos tiene un carácter subsidiario (entendido aquí como que son los organismos nacionales los que deben cesar y reparar internamente las violaciones a dichos derechos, correspondiendo al plano internacional solamente participar cuando no se había conseguido la protección interna), y, por ende, no constituye una cuarta instancia o grado destinada a revisar o anular decisiones jurisdiccionales tomadas, en este caso, por la judicatura ordinaria argentina.

d) Se invoca una aplicación de la teoría del margen de apreciación estatal.

e) Finalmente, la Corte Suprema argentina hace una invocación del artículo 27 de la Constitución de su país (por cierto, no comprendida sistemáticamente con lo prescrito en el artículo 75 inciso 22 de esa misma Constitución). En base a ello, señala la existencia de unos principios de Derecho público provenientes de la Constitución ( $y$, a tal caso, de los tratados sobre Derechos Humanos con jerarquía constitucional), los cuales están por encima de lo dispuesto en los diferentes tratados, a los que se les reconoce un rango supralegal pero infraconstitucional. La invocación de esos principios, junto a las otras consideraciones ya aquí invocadas en este texto, le permite a la Corte Suprema argentina, a la vez, preservar su sentencia y no materializar lo planteado en su momento por la Corte Interamericana.

Mucho es lo que se podría señalar al respecto, tema que abordaré con detalle en otros trabajos. Sin duda, como ya se ha invocado en algún texto reciente, siempre es necesario conversar sobre cuáles debieran ser los alcances y efectos de una sentencia de la Corte Interamericana. Además, añado, conviene siempre construir respuestas que sean producto de un diálogo interinstitucional multinivel. Sin embargo, ello no puede hacerse de cualquier manera.

Explico los alcances de esta última afirmación. Sin duda alguna siempre puede discutirse si un órgano jurisdiccional pasa, si de tutela de 
Cuando el juez(a) constitucional latinoamericano(a) olvida su labor de Convencionalización del Derecho: reflexiones en torno a una reciente sentencia de la Corte Suprema de Justicia de la Nación argentina When the Latin American constitutional judge forgets his/her job of conventionalization of law: reflections about a recent sentence of the Argentine Supreme Court of Justice.

derechos se trata, de, lo que bien señalaba Augusto Morello, de un necesario activismo a un riesgoso hiperactivismo en la comprensión de sus competencias. Sin embargo, no puede desconocerse que, en aplicación del principio KompetenzKompetenz, es a la Corte Interamericana a quien le corresponde determinar cuál es su margen de competencias. El resultado debe consensuarse, pero en base a un parámetro ya establecido (el convencional) y con respeto a las competencias reconocidas a los diferentes intérpretes involucrados.

Además de lo expuesto, debe mencionarse que la invocación al principio de subsidiariedad es muy respetable, pero errónea, pues en rigor no guarda relación con las medidas de reparación que puede fijar la Corte Interamericana de Derechos Humanos, escenario en el cual precisamente se desenvuelve esta controversia. Como bien conviene tener presente, este principio de subsidiaridad busca asegurar que la alegada violación de algunos derechos tenga una respuesta adecuada a nivel interno antes de eventualmente ir al escenario de la protección internacional de derechos. Una medida de reparación decidida por la Corte Interamericana es la consecuencia de un momento posterior: ya lo debatido escapó del conocimiento a nivel nacional. Ya tiene un pronunciamiento supranacional, acompañado de una serie de medidas destinadas a asegurar el cabal cumplimiento de dicho pronunciamiento.

También, con todo respeto, es equivocada la comprensión de la Corte Interamericana como una cuarta instancia o grado. La Corte Interamericana no hace evaluaciones en función al cumplimiento de respetables ordenamientos jurídicos nacionales. La Corte Interamericana evalúa si lo que se ha cumplido son los parámetros convencionales, previstos en la Convención Interamericana o en la interpretación contenciosa o consultiva que la misma Corte haya hecho de la misma Convención. No es pues un organismo de revisión de un ordenamiento jurídico estatal en base a las pautas de ese mismo ordenamiento jurídico estatal.

Sin embargo, las apreciaciones más preocupantes son aquellas vinculadas a la invocación del margen de apreciación estatal y a los principios de Derecho público incluidos en el artículo 27 de la Constitución argentina. Con cargo, repito, a volver a este tema en posteriores trabajos, la lógica del margen de apreciación estatal -por cierto muy cuestionada en el escenario europeo donde habitualmente se ha aplicado- va en un sentido muy distinto de la configuración del control de convencionalidad que se ha venido siguiendo en los países inscritos en el sistema interamericano de protección de derechos.

Y es que una cosa es tomar en cuenta las especiales características de lo que ocurre en un país para un mejor resolver, y otra condicionar la respuesta o su ejecución a la voluntad de organismos pertenecientes al Estado sancionado (o posible de sanción por violación de parámetros convencionales). Lo segundo, con todo respeto, conspira contra el sentido último de la convencionalización del Derecho, el de la construcción de un Derecho común. Un Derecho común no es pues el producto de lo que se quiera aceptar o se admita ejecutar. Debe ser más bien, como ya se ha adelantado en otro apartado de este mismo texto, el producto de consensos interpretativos mínimos

Es precisamente en mérito a esto último que la invocación hecha a los principios de Derecho Público en la sentencia en comento no solamente es incompleta, sino también preocupante. Incompleta, en primer lugar, pues, como bien anotan algunos autores ${ }^{(23)}$, el artículo 27 de la Constitución debe leerse de acuerdo con lo señalado en el artículo 75 inciso 22 de esa misma Constitución, y, sobre todo, con el segundo párrafo de ese inciso, en el cual se consagra la vigencia de un Estado constitucional y Convencional. La consagración de un Estado Convencional queda despojada de sentido y contenido si el plano convencional es desconocido o entendido como un elemento subordinado.

(23) En este sentido destaca nítidamente lo trabajado por Andrés Gil Dominguez. La Corte Suprema de Justicia y un inexplicable retroceso en materia de Derechos Humanos. http: //underconstitucional.blogspot.pe/2017/02/la-corte-suprema-de justiciay-un.htm 
Eloy Espinosa-Saldaña Barrera

Y es que el diálogo no implica que alguien tenga la razón per se, o que resuelva en función a cómo no solamente entiende sus propias competencias, sino también aquellas que son propias de los demás intérpretes involucrados. Menos aún que, en función de ese respetable razonamiento unilateral, se irrogue tener la última palabra en lo referido a la tutela de diversos derechos. Aquello, sensiblemente, no es generación de un Derecho común con una lógica tuitiva de los derechos ciudadanos, que es precisamente a lo que todo juez(a) constitucional (sin importar si es parte de la judicatura ordinaria o de un Tribunal Constitucional) debería apuntar, máxime si tomamos en cuenta el actual contexto mundial en general, y latinoamericano en particular, salvo mejor parecer.

\section{Breves apuntes a modo de conclusión}

A pesar de la desconfianza, en América Latina tradicional, cuando no endémica; en la labor de jueces y juezas constitucionales (sobre todo cuando quienes están dentro de la judicatura ordinaria), precisamente en mérito a un contexto difícil a nivel mundial y latinoamericano al respecto, las ventajas de la convencionalización del Derecho son a todas luces ostensibles. Ahora bien, esta convencionalización tiene (y seguramente tendría) que hacer frente a una serie de retos. El recientemente pronunciamiento de la Corte Suprema argentina a propósito de "Fontevecchia y D'Amico" nos demuestra cuáles son algunos de estos retos, presentando algunos de ellos bajo nuevas justificaciones.

Bienvenido entonces el análisis crítico e incluso la discrepancia, materia que analizaré con más detalle en otros trabajos. Ahora bien, creo que este caso corresponde respetuosamente apartarse de lo señalado con la mayor parte de los jueces supremos argentinos, e ir, en esa lógica de generación de consensos mínimos, procesando algunas eventuales imprecisiones (alcances de la convencionalización; configuración del escenario de diálogo; pautas de nombramiento, promoción y salida de los juzgadores(as) nacionales y supranacionales) vinculados. Lo ya obtenido gracias a la convencionalización del Derecho y la relevancia de los objetivos que apunta conseguir así lo reclamen, por lo menos en nuestro escenario latinoamericano. 